\title{
LA SOCIEDAD PANAMEÑA ANTE EL 2000: POLÍTICA Y ACTUALIDAD
}

\section{PANAMA TO THE SOCIETY 2000: POLICY AND PRESENT}

\section{AUTORA}

\section{Amparo Guerra Gómez}

Universidad Complutense de Madrid

amparo_guerra_g@eucmax.eim.ucm.es

\section{RESUMEN}

El Canal de Panamá siempre ha sido de gran interés norteamericano por su posición estratégica. El Presidente Carter fue el primero en dar un paso para negociar con los panameños la completa administración de éste. Las relaciones de Carter con Torrijos eran excelentes, pero en los 80 sufren un ligero revés. La sociedad panameña vive un intenso combate político entre partidos, siendo muy criticada Mireya Moscoso. El futuro depara problemas medioambientales para el Canal, apoyo de parte de la opinión pública norteamericana y los retos del desarrollo y la soberanía del país.

\section{PALABRAS CLAVE}

Canal- Nixon - Reagan- Política- Futuro 


\section{ABSTRACT}

The Panama Canal has always been of great interest to U.S. for its strategic position. President Carter was the first step to negotiate with the Panamanians complete management of it. Carter's relations with Torrijos were excellent, but in 80 suffer a slight setback. Panamanian society is experiencing a severe political struggle between parties, being heavily criticized Mireya Moscoso. Environmental problems lie ahead for the Canal, support from the American public and the challenges of development and sovereignty.

\section{KEY WORDS}

Canal- Nixon - Reagan- Politic- Future

\section{ÍNDICE}

1. Nación, territorio y soberanía: el canal de Nixon a Reagan.

2. El retorno de los líderes: populismo, caudillismo y electoralismo.

3. El futuro está aquí: retos y problemas para un milenio.

4. Bibliografía.

No es posible establecer un perfil sociocultural de Panamá si no es como territorio único del Nuevo Mundo, puente entre las Américas y zona de tránsito al Continente Sur y Suez del Hemisferio Occidental Mismos términos en los que lo define The $\mathrm{CIA}, \mathrm{S}$ 


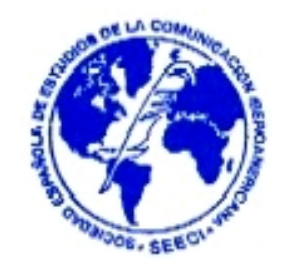

World Factbook 1996 . por su localización estratégica en el extremo oriental del istmo y porque controla el Canal de Panamá que une Atlántico Norte con Pacífico Norte vía Caribe; un área de 78.200 kilómetros cuadrados, menos que Carolina del Sur, con $2.490 \mathrm{~km}$. de costa y fronteras con Costa Rica y la gran Colombia, 800 km. de vía navegable (82 del Canal), con una trayectoria de modelo occidental, régimen constitucional presidencialista para una población de cerca de 3 millones de habitantes y economía basada en los servicios (banca, comercio, turismo), y. por tanto, enclave tradicional para inversiones extranjeras.

País llave en la diplomacia latinoamericana, pero de innegable vinculación histórica con el Norte, muy en particular con los Estados Unidos, desde la creación como república independiente a principios de siglo, ha marcado la trayectoria histórica de un país, istmo y apéndice hacia el rotundo cambio geográfico y lingüístico del Trópico. Un país americano e hispano. pero todo, y como ya lo definió el propio Torrijos, con una religión: la de su Canal, credo identificativo de una población que se enfrenta ahora a una situación tan deseada como temida: el acceso a la soberanía de una vía internacional que nació y ha permanecido ajena a sus intereses los últimos cien años.

Para quienes hemos tenido nuestro primer contacto investigador con el tema a través de sus implicaciones como área estratégica de la política exterior norteamericana, la visión de una sociedad que se enfrenta a su redefinición este fin del milenio esta indefectiblemente marcada por el futuro de esa vía entre océanos, cuya identidad no se acaba de creer aún ni partidos ni opinión pública. De ahí que, comenzando por los años 70. la controvertida titularidad, siga marcando et gran debate de la actualidad Panameña. Una larga marcha que comienza a vislumbrar la luz al final del túnel con la presidencia del demócrata Jimmy Cárter El tema del contencioso panameño cobra interés como uno de los más innovadores del programa de la New Age, muy ligado al espíritu postVietnam y a la progresión de la detente, 


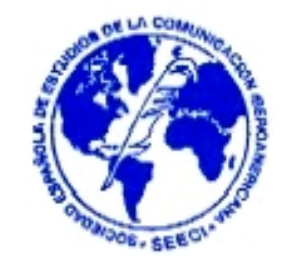

mediante paulatina de relaciones de Washington con países caribeños tradicionalmente cerrados, como es el caso de Cuba. No menor conexión proyecta el tema con una visión de interdependencia en relaciones exteriores y con el cumplimiento de lo que en su momento se considero un giro de $180^{\circ}$ en la dominante política hemisférica del Big Stick, final anticipado de la guerra fría con el que una Administración sureña reconoce la realidad multipolar imperante, pero que verá truncadas sus esperanzas a nivel global. La firma y aprobación de los tratados Carter-Torrijos fue uno de los grandes éxitos de un gobierno de forasteros, si bien dejó su herencia en la incógnita del cumplimiento de unos plazos al momento decisivo del último día de 1999.

¿Qué aportaba ya entonces la soberanía y que peligros conllevaba una total anexión? La historia reciente del Canal de Panamá es, en bastante medida. la de las presidencias norteamericanas que marcaron su evolución.

\section{Nación, territorio y soberanía: el canal de Nixon a Reagan}

Los 70 suponen la revisión del background político y económico de un país en crecimiento no exento de contradicciones., y en el que la cuestión del Canal resurge en un contexto internacional. Panamá es una nación con creciente peso de una opinión pública para la que la recuperación de su vía de agua es un instrumento de cambio y consolidación de instituciones modernas: régimen parlamentario, tendencia al bipartidismo, capitalismo en desarrollo, con su inevitable anverso : dependencia neocolonialista (multinacionales), baja renta per cápita. En medio el interés de una nación llamada a convertirse, por razones de urgencia, en emplazamiento de nuevos foros de paz internacionales.

La llegada de Cárter a la Casa Blanca supone un salto cualitativo a la revisión de las conversaciones en punto muerto desde los tiempos de Kissinger y Elsworth Bunker, último embajador con el que se trató la posible titularidad en un contexto de 


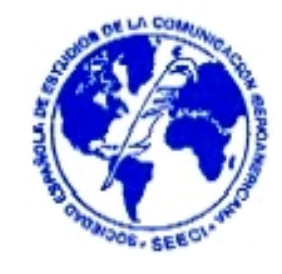

ampliación de Inversiones estadounidenses para una segunda vía de navegación bajo administración conjunta, propuesta rechazadas por el gobierno panameño. Las negociaciones de 1977, uno de los temas estrella del nuevo presidente, son llevadas con celeridad y excelentes relaciones con el líder del momento: Omar Torrijos. que llega a convertirse en un atípico amigo y aliado - papa general le llama Hamilton Jordán ', J efe de Staff de Cárter- con el que la Administración estadounidense podrá contar en breve a la hora de resolver ásperas cuestiones mundiales, y que se prestará a dar cobijo, en la isla de Contadora, a una destronada familia Pahlevi, y a su desahuciada cabeza, el otrora todopoderoso Sha de Persia.

La firma de los tratados en Washington, en el verano de 1977, por los que los Estados Unidos corrigen un error y terminan con una injusticia histórica. parece anunciar ese final provisional a la guerra fría que las superpotencias se apresuran a establecer con la consecución de un acuerdo, parte dos, de Limitación de Armas Estratégicas, de no tan afortunada conclusión. Aprobación y refrendo de unos resultados cuestionables a nivel del país de origen: oposición de panameños progresistas a un tratado hipotecado; de los norteamericanos destacados, zonians y funcionarios civiles, que ven peligrar sus cómodos puestos de trabajo. La lucha no es menor a nivel de Capitolio Washingtonjano: republicanos y demócratas conservadores, amen de destacados políticos y senadores (Reagan, Kissinger. Murphy. Goldwater, Hayakawa, De Concini). Sin olvidar a grupos económicos y de presión: lobby de Miami (relaciones torrijistas con Castro), multinacionales como la Standard Fruit Co. e incluso división entre congregaciones religiosa (mormones, baptistas). Los intereses militares $v$ estratégicos se expresan contundentemente por Pentágono $v$ altas instancias del Departamento de Defensa (pagamos por él y el Canal es nuestro). Los apoyos, de calidad e internacionales: Cárter y su Gabinete. Partido Torrijista y gobiernos de la OEA. Resultado del envite: aprobación en el Senado por 62 votos contra 32. El proyecto se había salvado con éxito. Solo quedaba esperar y repasar los contenidos formales, el espíritu pero también la letra, para 


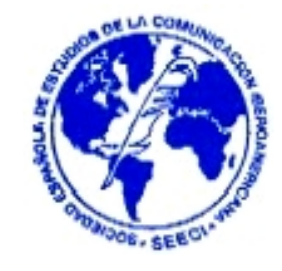

calibrar las verdaderas ventajas e inconvenientes de tan magna conquista sobre la tradicional política del good neighborhood.

Las ventajas más destacables de los Tratados corresponden a la situación de soberanía que, aunque escalonada (65\% de manera inmediata; restante hasta 31 de diciembre de 1999), vence a la cláusula original de perpetuidad extranjera. No menos desdeñable resulta la no presencia militar norteamericana en territorio panameño, además de la compensación económica, si bien con un importante recorte de mas de $\$ 50$ millones anuales. Pero son los inconvenientes hacen los que ponen de manifiesto el doble filo de una ruptura difícil; entrada en vigor tardía (en 1979) y, lo que es más evidente, soberanía ciertamente hipotecada a las condiciones de un Tratado de Neutralidad y Operabilidad, gol de última hora que subordinada la total titularidad a las condiciones exteriores (garantía de transito pacífico en tiempos de guerra o paz) en forma de sistema de protección y defensa conjunta.

Pros y contras de una transacción en ciernes, que pronto ha de pasar su prueba de fuego. Pese a lo manifestado por Ronald Reagan en la campaña a la Presidencia, los años 80 transcurren entre otras prioridades más sonadas, si bien con la prematura desaparición de su mayor artífice, ausente para e! evento de fin de milenio . Mientras que sus y sucesores son sustituidos por líderes más acordes con el gusto del viejo y nuevo establishment. Al final de la década sobreviene la crisis del torrijismo en la persona del general Manuel Antonio Moriega, buscado para su Juicio en territorio estadounidense, con un cambio en las relaciones que amenazan arruinar el futuro del Canal, y que se resuelven por la vía de la intervención para la entrega y juicio del fugado y supuesto narcotraficante Retroceso pues en una delicada progresión. Como tributo que $\mathrm{h}$ de pagar la presidencia de Guillermo Endara, y avance hacia la recuperación del arnulfismo en el exilio de Miami. 


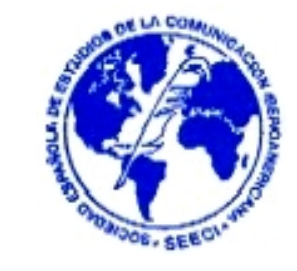

\section{El retorno de los líderes: populismo, caudillismo y electoralismo.}

El gran reto corresponde indudablemente a la última década de siglo. Vísperas y final del mandato de Ernesto Balladares, en el que herederos del antiguo y nuevo orden se disputan algo más que la jefatura de Estado: et presidir la materialización de un cambio histórico estrechamente seguido por medios y ciudadanía como imagen de la democracia del nuevo milenio.

Mireya Moscoso, ex de Gruber y Martín Torrijos, ambos candidatos con sus programas de renovación y continuidad, coincidiendo en sus actividades con otros favoritos: en una acalorada primavera a concluir con el triunfo de la viuda del tres veces presidente encabezando la lista de Unión por Panamá. Perfiles de figuras de su época, que difieren sin embargo en edad (35 él. 53 ella) y background. Mientras que el vástago del famoso general es un ex militar y graduado en Ciencias Políticas y Económicas por el College Station de la Texas A\&M University con experiencia laboral en la Industria norteamericana y reciente participación política en el gabinete Pérez Valladares; la dama del arnulfismo tiene en su haber, además de la convivencia, un diploma comunitario de Diseño de Interiores, que añadir a su experiencia laboral americana (secretaria ejecutiva y sales manager), que no evitó una primera derrota en 1994.

Eso sí, ella afirma estar en el puesto gracias a la ampliación que su tan criticado marido hizo extensiva a la mujer poco antes de su derrocamiento. Distintos pero ambos con una misma estrategia- señala John Otis-:la utilización de la mística del parentesco famoso, puesta de manifiesto en declaraciones públicas, consignas e iconografía de unos cuarteles generales que alejan cualquier ambigüedad, aunque con ideología renovada que no logra convencer a expertos y analistas sobre la herencia, improbable, de ese carisma que podría identificar a Martín como político 


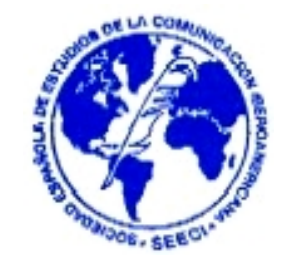

ante un electorado que recuerda a sus mitos y para quien Moscoso se antoja una versión "light" de Evita Perón.

Sobre los respectivos programas. avance democrático, austeridad gubernamental y participación ciudadana titulan las propuestas de un PRD -Alianza hacia una Nueva Nación- que se detiene en todo lo relacionado con la próxima soberanía sobre el Canal y sus problemas como asuntos de Estado y. en consecuencia, sometidos aun amplio consenso nacional, comprometiéndose, no solo a respetar el ordenamiento jurídico alcanzado sino a buscar la ampliación de su capacidad para el siglo que viene. Por su parte, la coalición Unión por Panamá aborda la revisión popular de una herencia transformada en neoliberalismo. Que la asociación MONADESCO califica de poco comprometido con los trabajadores, mientras que no se acaba de definir en cuanto a la permanencia o no de las bases norteamericanas territorio nacional.

Como era de esperar la campana transcurre con declaraciones v ataque cruzados de los que se hacen eco los medios de alcance nacional y local, criticando y/o tomando partido ante lo que consideran irrespeto al arnulfismo, manzana de la discordia, 0 precedente nefasto: el anuncio público de la propuesta del banquero Alberto Vallarino (Acción Opositora) al PDC, rompiendo el compromiso de consolidar una eficaz alianza opositora. Durante el otoño de 1998 la figura de la candidata no sale demasiado bien parada en la prensa progresista por sus actuaciones a nivel público y particular: heredera de las truculentas elecciones en el arnulfismo y condenada a una derrota casi segura como responsable, con su camarilla de asesores, de la desunión de la oposición mayoritaria; tramposa y mala paga como patrona, que retiene salarios y debe 15.000 dólares en concepto de cuotas al Seguro Social.

El peligro de tales disidencias, nuevo fallo en las negociaciones, es por todos conocido refuerza en la opinión pública la imagen de un duelo histórico entre Arnulfistas, Liberales y Torrijistas. fuerzas dominantes en la política panameña desde décadas, y adjudica mayores posibilidades al partido en el poder, como ya sucedió 


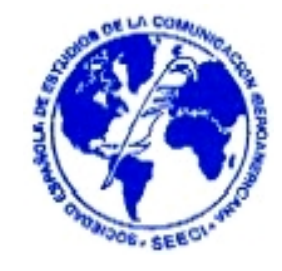

en 1994, cuando incluso un advenedizo como el cantautor Rubén Blades vio crecer su popularidad pese a una larga ausencia del país y a la indefinición de su candidatura. Rivalidades que según algunos perjudican ante todo a los ciudadanos.

¿Por qué el odio contra Mireya Moscoso? se pregunta en los medios algún dirigente públicos, refiriéndose a los ataques de quienes deberían constituirse en aliados, como el caso de su paisana la Mayín Correa, que comparte sexo y humilde origen con la primera fémina que opta a la máxima candidatura en el país, en vez de apoyarla o incluso formar con ella terna presidencial, algo verdaderamente innovador e imbatible en los próximos comicios, mientras que. Con su público rechazo -asegura el firmante-la alcaldesa no hace sino dividir a la oposición y facilitar la continuación del PRD (la estrategia yerno-suegro) obstaculizando la llegada al poder de la candidata, cuando todavía están frescas en la memoria del país las consecuencias de los resultados de cinco años atrás: nefasto y deshumanizante gobierno del Dr. Pérez Balladares que el pueblo ha tenido que soportar y al cual la población panameña el 30 de agosto de 1998 le dijo nunca jamás. Que Mayín recapacite v no repita el triste papel de un Rubén Darío Caries. Menos inflar el ego y más recordar que "Un Pueblo Unido jamás Será Vencido"

A menos de dos meses de las generales, las encuestas (Cid-Gallup y Dichter and Neira) adjudican la victoria a! Partido Revolucionario Democrático con Martín Torrijos favorito (40-45\% de votos) entre los electores del interior y jóvenes con educación secundaria, mientras que Moscoso desciende a! 30-32\% (electorado adulto con formación primarla) y Alberto Vallarino acapararía la intención de voto de población urbana y universitaria (20-17\%). Triunfalismo populista cuyos vítores ya han proclamado en los rotativos Alberto S. Barrow N. (1999, año de Torrijos.) consignando otra memoria histórica: la de 1977. año de los Tratados y del líder que ha contribuido a nuestro devenir como Estado-Nación en lo que esa firma apunta hacia la materialización de nuestra independencia definitiva, Ernesto A. Quijada Díaz 


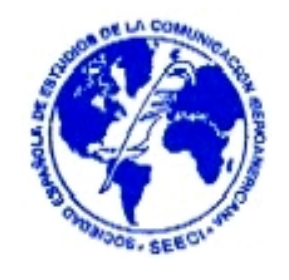

v Francisco A. Porras en La Estrella de Panamá, enraizando los méritos de dos generaciones. A Ornar, hombre justo en el sentido material e inmaterial del vocabloen palabras del Padre Villalobos, preocupaba de no faltar el respeto para que no se lo faltasen-y de tan profunda influencia para otras jóvenes revoluciones de Centroamérica, y al licenciado que hoy acaudilla la alianza Nueva Nación, que ha cautivado al público por el talante social de sus propuestas, y por su liderazgo político y de masas, bien demostrado ante las cámaras en los recientes debates públicos (En la mira), donde se mueve con acierto, entereza, solvencia, conocimiento de los temas a explicar y, sobre todo. con un alto espíritu de exhortación a todos los sectores de la vida pública a integrarnos como nación en las tareas de desarrollo que esperamos se cumplan. Actuación brillante de la que ha salido y que sumó a su favor a un alto porcentaje de ciudadanos indecisos.

Llegado el momento de la verdad, los resultados de uno de los pocos suframos puros y cristalinos desde 1903: los presididos por Ernesto de la Guardia Hijo. Guillermo Endara y Pérez Balladares, elecciones poco o nada se corresponden con tales pronósticos. Con el 76\% de participación, el 45\% (563.921) para la postulante de Unión por Panamá, con Vallarino (219.450), como primer Vicepresidente. Segundo en resultados aparece Martín Torrijos (474.477), que se enfrenta ahora a un posible conflicto entre las dos facciones del PRO. Entre los partidos que desaparecen. al no obtener representación: Papa Egoro. De Blades, Renovación Civilista. Morena, PNP y Partido Liberal, de J oaquín Fernando Francoli.

En cuanto a la explicación del vuelco experimentado en el definitivo baño de multitudes, un repaso a las páginas de opinión internacional apunta lo que han sido las claves del éxito del arnulfismo en el siglo XXI. Ante todo, recuperación del mito populista de los 40. El eje vital de la campaña de Moscoso- señala Bob Pastor a Reuters el 3 de mayo de 1999- fue un compromiso con los menos privilegiados de este país de 2.7 millones de habitantes, que sufren de una tasa de pobreza del 36\% 


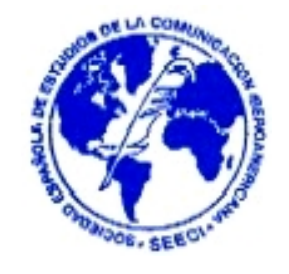

y un desempleo del $12,8 \%$. Lo que en definitiva propone la presidenta electa es volver la mirada a ese pueblo olvidado por su antecesor-, un Luis XIV de su tiempo para su colega Endara-mejorando los servicios sociales y programas de ayuda a los mas necesitados con los beneficios de las privatizaciones (fondo de 1.400 dólares creado por el PRD). La gran Incógnita para los observadores internacionales, sigue siendo si la exultante Mireya podrá nadar y guardar la ropa. haciendo compatibles las promesas de un proyecto nacional con las realidades de una sociedad globalizada.

Los peligros acechan ahora para la oposición torrijista, temerosa de que el nuevo gobierno, que tomará posesión de sus cargos el primer día de septiembre, reanude las negociaciones para la permanencia de las bases militares norteamericanas después del 2000 , bajo el pretexto de la creación de un Centro Multilateral AntiDrogas en la zona del Canal, propuesta que Washington podría hacer amparándose en las cláusulas del Tratado de Neutralidad y Operabilidad, y en e! problema de la seguridad de la tontera con Colombia, según puede interpretarse de la reciente visita de Kenneth Mac Kay, enviado especial del presidente Clinton, quien mantuvo una entrevista de 3 horas con la Presidenta electa. Incertidumbre que refrenda el todavía Jefe del Ejecutivo doctor Pérez Balladares"., mientras que las declaraciones de la recién llegada, ahora en conversaciones con el PRD para la transición del poder, aseguran que el cumplimiento, en los plazos previstos y que incluyen el fin de esta presencia exterior, no invalida la disposición de su futuro gobierno a dialogar con los EE.UU. en materia de seguridad continental y lucha contra el narcotráfico.

Reticencias a las que se enfrenta la primera mujer llegada al cargo de la historia de Panamá a través de unas elecciones que, según manifiesta el Presidente del Tribunal Electoral, Eduardo Valdez, contó con tres excelentes opciones presidenciales para unos comicios que los observadores internacionales han caracterizado por su transparencia (felicitación de la Presidenta a Pérez Balladares), y en las que resultó crucial la labor de la Fuerza Pública como custodios de actas electorales, algo 


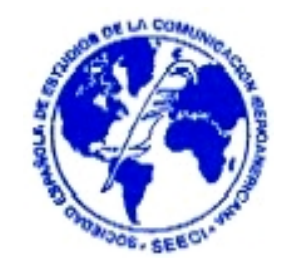

impensable hace unos años. Mieles de triunfo para quien promete gobernar con abnegación, serenidad y espíritu de solidaridad, pero también duros desafíos para Moscoso -concluye Valdez-, que tendía que borrar la Imagen de que Panamá, por su posición estratégica, sirve de trasiego de drogas hacia otros países, especialmente los Estados Unidos.

\section{El futuro está aquí: retos y problemas para un milenio}

Más allá de la visión popular que quieren dar las élites, las Inquietudes de los panameños como nación conservan la liquida mirada de su centro vital, ese Canal, razón de ser y más preciada pertenencia en una era dominada a partes iguales por capitalismo y Ecología, religión a su vez para las generaciones del siglo XXI, y que las fuerzas vivas del país no quieren ni pueden ignorar. Con una sociedad multirracial un nivel relativo de bienestar solo superado por la vecina Costa Rica. el futuro del Istmo sigue moviendo en et binomio Norte/Sur, entre americanismo y nacionalismo propio, dicotomía que se extiende a la incógnita de alcanzar un desarrollo sostenible que no evite la condenación de su territorio a la única categoría de paraíso turístico y centro de inversiones extranjeras. Para ello resulta imprescindible preservar riquezas de transformación pero también biodiversidad de un paisaje de gran riqueza científica y medioambiental.

Este es el aspecto que preocupa a grupos y asociaciones ciudadanas a la hora elaborar a los presupuestos del Estado. No solo el traspaso de la propiedad, sino de la gestión, el mantenimiento una vía de transito internacional de las características de la existente En este final de década en que el ex presidente Jimmy Cárter, condecorado con la máxima distinción panameña: la Cruz de Balboa, por su contribución a la mejora de las relaciones entre los EE.UU., este país y Latinoamérica en general, ha visto secundada su labor por la risita de Hillary Clinton. En la firma de un fondo para el Instituto Interamericano de Derechos Humanos, la preocupación de 


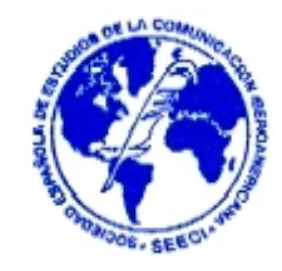

la Primera Dama ha ido mas allá: al problema de la deforestación de la zona, tema preferente en la consecución de una legislación de igualdad de oportunidades para ambos sexos.

La cuestión no cuenta ni mucho menos con el consenso de las partes, en este caso , las naciones implicadas, y la llamada de atención por la degradación futura del medioambiente en la zona del Canal, ecosistema altamente sensible a erosión, es motivo permanentemente de divergencia entre la actual dirección y las asociaciones panameñas de uno y otro signo. Mientras que hay quienes esperan que et control de los propios recursos naturales se haga posible con el traspaso de los mismos, otros recetan de la supervivencia de los bosques tropicales circundantes al Canal una vez los norteamericanos abandonen su administración. Es sabido que, en las últimas décadas se ha perdido un $70 \%$ de espacio arbóreo del territorio panameño, y no es seguro que la protección practicada hasta ahora en las orillas de la vía de agua continué bajo jurisdicción propia -asegura Iván Valdespino de la Asociación Nacional para la Conservación de la Naturaleza (ANCON)-, teniendo en cuenta el avance de la roturación de terrenos que podría alcanzar a lo que ahora son reservas y parques nacionales.

Aunque el problema real no son los granjeros sino la expansión incontrolada de las áreas urbanas. Crecimiento que conlleva erosión y polución que afecta a las reservas de agua. No solo para el Canal, sino para las ciudades y pueblos. Para conservacionistas, si bien la población está altamente concienciada de la necesidad de proteger leste ecosistema, la comunidad internacional no parece tomar cartas para garantizarl'- insiste Valdespino, firme partidario de que haya un seguimiento a nivel mundial. Recientemente se ha puesto de manifiesto que no hay que esperar tanto para ver accidentes (incluso delitos) ecológicos, si tenemos en cuenta las características circulatorias, tráfico pesado, que ha de soportar este gran trayecto; así, y con la polémica electoral en su punto álgido, se registraba un vertido de (42 


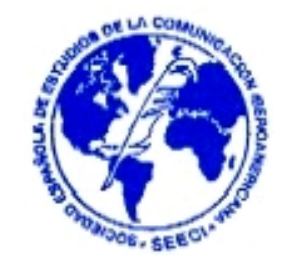

galones de petróleo) producto de la negligencia de la Atlantic Pacific S.A., afectando a la zona de Colón". Hechos y circunstancias que no son ciertamente atribuibles a una u otra titularidad, solo al cumplimiento de unas normas de seguridad que trasgreden las compañías, pero cuyo cumplimiento deberían garantizar las autoridades de todos y cada uno de los Estados afectados.

En cuanto al sentir de u opinión pública en el vecino del Norte, las asociaciones humanitarias norteamericanas rechazan de plano la permanencia militar estadounidense mediante esa vía/disfraz de la lucha internacional contra la droga, postura defendida por el interlocutor de la Administración, John Negroponte. un ex coordinador de la Contra nicaragüense en tiempos de Reagan, ya que carece de sentido no solo por ser un ataque a la soberanía reconocida de aquel país, sino por su ineficacia, (fondos que pueden ser desviados para operaciones encubiertas), además de rechazada por partidos y grupos de presión panameños como un obstáculo al desarrollo nacional. Eso sin contar que los 200 millones de dólares/año de su mantenimiento, que podrían destinarse a otros fines más urgentes como educación, trabajo o bienestar social.

Propiedad y soberanía total que pueden abrir mas de una puerta: al desarrollo, a la consolidación de la democracia, o al total reconocimiento en la diplomacia internacional. Porque, desde 1983, Panamá ha sido anfitrión del Grupo de Contadora, foro reunido en la isla del mismo nombre agrupando a los Ministros de exteriores de Colombia, México, Panamá y Venezuela como organismo clave para la pacificación de Centroamérica. Establecido su Cuartel General en México D.F., y a petición la Comisión Política del Parlamento Centroamericano (PARLACEN). esta porción del Archipiélago de Las Perlas fue testigo el 22 de agosto de 1996 del fin de inestabilidad guatemalteca, con la Declaración de Contadora (IV Conferencia Centroamericana de Partidos Políticos) suscrita por el organismo regional con la Comisión de Paz del Gobierno de Guatemala (COPAZ) y la Unidad Revolucionaria 


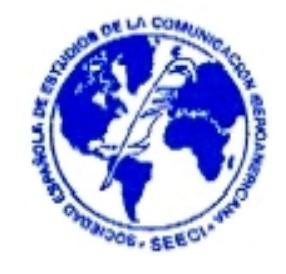

Nacional Guatemalteca (URG) para (alcanzar negociaciones de paz y convocar próximas elecciones; un compromiso mutuo de respetar las actividades de partidos políticos e instituciones nacionales e internacionales que, a su vez, facilite la reinserción de la guerrilla, previa deposición de las armas.

Cumplidas dos décadas de una firma histórica, solo queda esperar si el segundo milenio será el de Panamá. el del arranque definitivo de un país realmente abierto , conocido y considerado en el mundo entero como algo mas que el enclave de. Como nación que, con el Canal, ha tomado también las riendas de su propio destino, y que apuesta fuerte por su consolidación como sociedad avanzada y estable con lugar propio dentro v fuera de su continente. 